\title{
Utilização de levedura íntegra e seus derivados em dietas para juvenis de tilápia do Nilo
}

\author{
Utilization of sugar cane yeast and its by-products in Nile tilapia diets
}

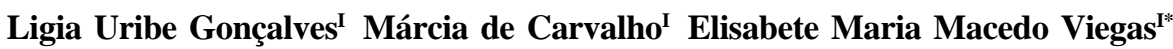

RESUMO

Neste trabalho, avaliou-se a adição de células íntegras de levedura e seus derivados em dietas para juvenis de tilápia do Nilo. Foram utilizados 144 juvenis machos de tilápia (peso médio de 52,1g) distribuídos em 12 tanques de fibra de vidro (250L), em delineamento inteiramente casualizado, composto por quatro tratamentos e três repetições. Os peixes foram alimentados ad libitum, duas vezes ao dia durante 60 dias, com dietas isoproteicas (28\% PB) e isocalóricas (2.900 kcal de ED $\mathrm{kg}^{-1}$ ) contendo levedura íntegra de cana-deaçúcar (LI), levedura autolisada (LA) e parede celular (PC) adicionados na proporção de $25 \%$ da proteína bruta total, comparadas com uma dieta controle (CO), sem adição de levedura. Não foram observadas diferenças significativas para conversão alimentar aparente e taxa de eficiência protéica. No entanto, o ganho em peso foi melhor nos peixes alimentados com as dietas LA $(114,70 \mathrm{~g})$ e PC $(131,03 \mathrm{~g})$, assim como em relação à taxa de crescimento específico ( $L A=1,79$ e $P C=1,93 \%)$, à proteína bruta no ganho de peso ( $L A=14,45$ e $P C=15,62 \%)$ e ao conteúdo corporal proteico $(L A=14,89$ e

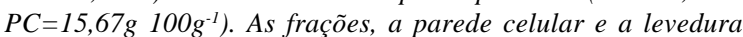
autolisada de cana-de-açúcar podem ser utilizadas em dietas para juvenis de tilápia.

Palavras-chave: Oreochromis niloticus, levedura de canade-açúcar, desempenho zootécnico, parede celular, levedura autolisada, Saccharomyces cerevisiae.

\section{ABSTRACT}

This study has evaluated the effect of adding dried yeast and its by-products in diets for juveniles of Nile tilapia. It was used 144 juveniles of male tilapia (average weight of 52.1g) distributed in 12 fiberglass tanks (250L), in completely randomized design, composed by 4 treatments and 3 replicates. The fish were fed ad libitum, 2 times per the day during 60 days, with isoproteic $(28 \% \mathrm{CP})$ and isocaloric diets $(2.900 \mathrm{kcal}$ ED $\mathrm{kg}^{-1}$ ) with dried yeast of sugar cane (LI), disrupted yeast cells (LA) and yeast cell wall (PC) added in the ratio of $25 \%$ of the total crude protein, compared with a control diet (CO), without yeast addition. No significant differences were observed for feed conversion and proteic efficiency rate. However, the weight gain was better in the fish fed with diets LA (114.70g) and PC $(131.03 \mathrm{~g})$, as well as in relation to the specific growth rate ( $L A=1.79$ and $P C=1.93 \%)$, crude protein in the weight gain ( $L A=14.45$ and $P C=15.62 \%$ ) and body protein content ( $L A=14.89$ and $\left.P C=15.67 \mathrm{~g} 100 \mathrm{~g}^{-1}\right)$. The by-products, cellular wall and disrupted yeast cell of sugar can be used in diets for tilapia juveniles.

Key words: Oreochromis niloticus, sugar cane yeast, disrupted yeast cells, yeast cell wall, Saccharomyces cerevisiae.

\section{INTRODUÇÃO}

A levedura de cana-de-açúcar (Saccharomyces cerevisiae) é frequentemente utilizada em dietas para animais pelo seu alto valor nutritivo: 43\% de proteína bruta, bons níveis de aminoácidos essenciais (lisina 3,5\% e treonina 3,5\%), 3000kcal de energia digestível $/ \mathrm{kg}$ de ração e $0,8 \%$ de fósforo (OZÓRIO et al., 2003). Na alimentação de peixes, esse ingrediente e seus derivados apresentaram resultados positivos como substitutos da farinha de peixe (PÁDUA, 1996; OLIVA-TELES \& GONÇALVES, 2001), de fontes de vitaminas hidrossolúveis (BACCARIN \& PEZZATO, 2001), de alimentos funcionais (GAIOTTO, 2005; WATANABE, 2006, PEZZATO, 2006; HISANO

IDepartamento de Zootecnia, Faculdade de Zootecnia e Engenharia de Alimentos (FZEA), Universidade de São Paulo (USP). Av. Duque de Caxias Norte, 225, 13635-930, Pirassununga, SP, Brasil. E-mail: emviegas@usp.br. *Autor para correspondência. 
et al., 2007a), de pró-nutrientes (HISANO et al., 2007b) e de imunoestimulantes (ORTUÑO et al., 2002; LI E GATLIN, 2003).

Valores de até 50\% de inclusão de levedura em dietas para trutas (Oncorhynchus mykiss) foram recomendados por RUMSEY et al. (1991). Para tilápia do Nilo, FURUYA et al. (2000) recomendaram o nível de $14 \%$ de adição, e MEDRI et al. (2000) testaram diferentes níveis de até 30\% de inclusão e não encontraram nenhum efeito prejudicial no desempenho zootécnico. A divergência nos resultados pode estar relacionada à composição nutricional da levedura, uma vez que podem ocorrer variações na metodologia de produção, além da origem e do meio onde são cultivadas. Entretanto, o processamento da levedura (autólise e fracionamento) permite reduzir boa parte das diferenças do valor nutricional encontrados em ingredientes oriundos da indústria cervejeira e da produção do álcool (YAMADA et al., 2003).

A inclusão de 1,2 e $4 \%$ de levedura de cervejaria na dieta de híbridos (Morone chysops $x$ Morone saxatilis) proporcionou bons índices de ganho de peso, 20\% maiores em relação ao tratamento arraçoado com a dieta sem inclusão de levedura (LI e GATLIN III, 2003). Outros autores (MEURER et al. (2000)) adicionaram níveis crescentes de levedura spray-dried (0 a 6\%) nas dietas de alevinos de tilápia do Nilo e verificaram melhora linear para o peso, o comprimento, a taxa de eficiência proteica e a conversão alimentar em relação ao aumento do nível de levedura. Resultados positivos da inclusão de levedura também foram encontrados por HISANO et al. (2007) em tilápiado-nilo, pois os peixes que receberam rações suplementadas com levedura e derivados apresentaram índice de desempenho produtivo superior à dieta sem os ingredientes teste, destacando-se a levedura autolisada, a qual proporcionou desempenho superior aos demais tratamentos quando utilizada entre 1,30 e $1,59 \%$. Além do desempenho zootécnico, a levedura pode estar relacionada com a melhoria do sistema imunológico, como foi observado por GATLIN III \& LI (2005), em estudo no qual foi verificada a redução na mortalidade de striped bass desafiados com bactérias patogênicas $\boldsymbol{S}$. iniae após o emprego de levedura na alimentação em razão da maior atividade respiratória dos neutrófilos e dos macrófagos dos rins.

Dessa forma, um experimento foi conduzido para avaliar o desempenho produtivo e a composição da carcaça de juvenis de tilápias do Nilo submetidos a dietas contendo levedura íntegra e seus derivados.

\section{MATERIAL E MÉTODOS}

A pesquisa foi conduzida no Laboratório Úmido de Nutrição e Alimentação Artificial de Peixes do Centro de Pesquisa e Gestão de Recursos Pesqueiros Continentais (CEPTA/IBAMA), situado no Município de Pirassununga, São Paulo (SP), a 21 56'17” de latitude sul e 47 22' 23" de longitude oeste, a 575m acima do nível do mar. Foram utilizados 144 juvenis machos, revertidos sexualmente, com peso médio de 52,1g e distribuídos em 12 caixas de fibra de vidro, com capacidade de 250L e abastecidas individualmente em sistema aberto.

O delineamento experimental foi o inteiramente casualizado, com quatro tratamentos e três repetições. Foi considerado como tratamento a inclusão de levedura íntegra ou seus derivados e como unidades experimentais 12 caixas de 250L contendo 12 peixes.

O monitoramento dos parâmetros físicoquímicos da água utilizada no trabalho foram avaliados diariamente para temperatura e oxigênio dissolvido e semanalmente para $\mathrm{pH}$, alcalinidade, amônia total e dureza, todos no período da manhã (9h). A temperatura da água foi monitorada com termômetro de bulbo de $\mathrm{Hg}$ posicionado a $15 \mathrm{~cm}$ de profundidade; a concentração de oxigênio dissolvido foi determinada utilizando-se um oxigenômetro (YSI-Modelo 57) provido de um termistor acoplado à sonda; o pH foi mensurado por meio de potenciômetro digital (B278Micronal); e para as determinações das concentrações de amônia e nitrito foi empregado o método de espectofotometria, com leituras em comprimentos de onda de 425 e 543 manômetros.

A levedura íntegra, levedura autolisada e parede celular foram doadas pelo Instituto de Tecnologia e Alimentos (ITAL), Campinas, SP, e os outros ingredientes utilizados na confecção das dietas experimentais foram adquiridos no comércio da região de PirassunungaSP. Todos os ingredientes e dietas experimentais foram analisados quanto à composição centesimal, segundo metodologia da AOAC (1990).

Quatro dietas isoproteicas (28\% de proteína bruta) e isoenergéticas (2.900kcal de $\mathrm{ED} \mathrm{kg}^{-1}$ ) foram formuladas visando a atender as exigências da tilápia do Nilo (NRC, 1993), sendo uma dieta controle (CO), sem adição de levedura, e três com ingredientes teste: levedura íntegra (LI), levedura autolisada (LA) e parede celular de levedura (PC), na proporção de $25 \%$ da proteína bruta total (Tabela 1). Os ingredientes foram triturados em moinho com peneira de $1 \mathrm{~mm}$, homogeneizados e peletizados (Peletizadora Califórnia Pellet Meal) em malha de $5 \mathrm{~mm}$. 
Tabela 1 - Composição percentual dos ingredientes e composição centesimal das rações experimentais.

\begin{tabular}{|c|c|c|c|c|}
\hline \multirow[t]{2}{*}{ Ingredientes (\%) } & \multirow[b]{2}{*}{$\mathrm{CO}$} & \multirow[b]{2}{*}{ LI } & \multirow[b]{2}{*}{ LA } & \multirow[b]{2}{*}{ PC } \\
\hline & & & & \\
\hline Farinha de peixe & 10,00 & 9,00 & 9,00 & 12,00 \\
\hline Farelo de soja & 38,00 & 26,00 & 24,00 & 28,00 \\
\hline Farelo de trigo & 15,00 & 10,00 & 8,00 & 3,00 \\
\hline Milho & 32,50 & 27,00 & 32,20 & 4,00 \\
\hline Levedura íntegra & - & 20,20 & - & - \\
\hline Levedura autolisada & - & - & 19,80 & - \\
\hline Parece celular & - & - & - & 42,50 \\
\hline Óleo de soja & 2,50 & 5,80 & 5,00 & 8,50 \\
\hline Suplemento vitamínico e mineral ${ }^{1}$ & 1,00 & 1,00 & 1,00 & 1,00 \\
\hline Aglutinante (caulim) & 1,00 & 1,00 & 1,00 & 1,00 \\
\hline \multicolumn{5}{|l|}{ Nutrientes } \\
\hline Matéria Seca & 94,03 & 93,78 & 93,14 & 95,30 \\
\hline Proteína bruta & 29,14 & 30,18 & 29,53 & 30,86 \\
\hline Extrato etéreo & 5,75 & 8,45 & 7,73 & 10,43 \\
\hline Fibra bruta & 4,56 & 3,34 & 3,22 & 2,71 \\
\hline Matéria mineral & 7,58 & 7,66 & 7,03 & 7,70 \\
\hline Cálcio & 0,92 & 0,90 & 0,82 & 1,13 \\
\hline Fósforo & 0,51 & 0,49 & 0,48 & 0,56 \\
\hline Energia digestível ${ }^{2} \mathrm{Kcal} \mathrm{kg}^{-1}$ & 2918,05 & 2932,73 & 2919,31 & 2877,19 \\
\hline
\end{tabular}

1 - Composição do suplemento mineral e vitamínico (níveis de garantia por kg de suplemento) - ácido pantetônico=5.000mg; antioxidante=0,25g; cobalto=24,999mg; cobre=1.999,9mg; ferro=11.249,7mg ; iodo=106,2mg; manganês=3.749,9mg; niacina=3.750mg; selênio=75,5mg; vitamina $A=1.000 .000 \mathrm{UI}$; vitamina $B 1=250 \mathrm{mg}$; vitamina $\mathrm{B} 12=2.500 \mathrm{mg}$; vitamina $\mathrm{B} 2=1.750 \mathrm{mg}$; vitamina $\mathrm{B} 6=875 \mathrm{mg}$;

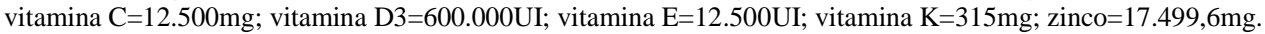

2 - Estimada segundo National Research Council (1993).

Os peixes foram alimentados ad libitum com as dietas experimentais duas vezes ao dia (9 e 17h), por um período de 60 dias e as caixas foram sifonadas três vezes por semana para retirada de fezes e restos de ração. No início do experimento e aos 30 e 60 dias, os peixes foram anestesiados por meio de banhos de imersão de dois minutos em solução contendo $2 \mathrm{ml}$ phenoxethenol diluídos em 10 litros de água para facilitar o manejo e diminuir o estresse durante as biometrias. Ao final do experimento, foram calculados os seguintes parâmetros:

-Ganho de peso (GP) = peso final - peso inicial

-Consumo médio diário de ração (CMD) = consumo de ração no período experimental número de peixes

- Conversão alimentar aparente (CAA) = consumo de ração

ganho de peso

- Taxa de eficiência proteica (TEP) = ganho de peso

consumo de proteína bruta da dieta
- Taxa de crescimento específico (TCE) =

Ln(peso total) - Ln (peso total inicial) tempo do experimento (dias)

-Proteína bruta no ganho de peso (PBGP) = (PBCF x PMF) x (PBCIxPMI) x 100, em que: Peso final - Peso inicial

PBCF: Proteína bruta corporal final; PMF: Peso médio final; PBCI: Proteína bruta corporal inicial; PMI: Peso médio inicial

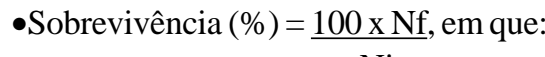
$\mathrm{Ni}$

$\mathrm{Nf}$ = número de peixes no final do experimento; $\mathrm{Ni}$ = número de peixes no início do experimento

Para cálculo da porcentagem de proteína bruta no ganho de peso (PBGP), foram sacrificados seis exemplares de peixes de cada tratamento no início e final do experimento para determinação da composição centesimal corporal, segundo a AOAC (1990). Os resultados obtidos foram submetidos à análise de variância e, em caso de diferenças 
significativas, as médias foram comparadas pelo teste de Tukey $(\mathrm{P}<0,05)$, utilizando-se o programa Statistical Analysis System (SAS, 1996).

\section{RESULTADOS E DISCUSSÃO}

Durante o período experimental, os valores médios de temperatura, oxigênio dissolvido, $\mathrm{pH}$, amônia e dureza da água foram de $24,75^{\circ} \mathrm{C} \pm 1,67$; $5,70 \pm 0,51 \mathrm{mg} \mathrm{L}^{-1} ; 5,94 \pm 0,42$ e $0,06 \pm 0,007 \mathrm{mg} \mathrm{L}^{-1}$ e 7,99 1 1,01 de $\mathrm{CaCO}_{3} \mathrm{mg} \mathrm{L}^{-1}$ considerados satisfatórios para o desenvolvimento de peixes tropicais (ARANA, 2004). Os valores médios observados de alcalinidade (8,76 $\pm 0,71 \mathrm{mg} \mathrm{L}^{-1}$ ) apresentaram-se abaixo do ideal (20 a 300 $\mathrm{mg} \mathrm{L}^{-1}$ ), evidenciando uma baixa capacidade tamponante da água.

Não foram observadas diferenças significativas $(\mathrm{P}>0,05)$ para Conversão Alimentar Aparente e Taxa de Eficiência Proteica entre os tratamentos. No entanto, os peixes alimentados com a parede celular (PC) e levedura autolisada (LA) apresentaram maiores ganhos de peso e melhores valores em relação à taxa de crescimento específico e proteína bruta no ganho de peso em relação aos demais tratamentos $(\mathrm{P}<0,05)$ (Tabela 2), e o tratamento LA não diferiu significativamente em relação aos tratamentos com levedura íntegra (LI) e a dieta controle (CO).

Para o parâmetro consumo médio diário de ração (CMD), foram observados maiores valores
$(\mathrm{P}<0,05)$ para os tratamentos PC e LA (40,83 e 35,69g, respectivamente), porém o tratamento LA não diferiu significativamente em relação aos tratamentos com levedura íntegra (LI) e a dieta controle (CO) (Tabela 2). Segundo PEREIRA DA SILVA \& PEZZATO (1999), a levedura de cana-de-açúcar é considerada um ingrediente de média atrato-palatabilidade para tilápias do Nilo. HISANO et al. (2007a) confirmaram seu potencial como ingrediente atrato-palatabilizante, que pode estar relacionada à composição e concentração dos aminoácidos. A levedura autolisada é um produto que tem sido utilizado em alimentos para humanos como uma forma de melhorar suas propriedades sensoriais, realçando o sabor da carne, por exemplo. O ácido glutâmico apresenta-se em elevada concentração na levedura autolisada e no extrato de levedura e, juntamente com nucleotídeos, deve ser o principal responsável pelo sabor à dieta. Portanto, a levedura autolisada e a parede celular utilizadas como ingredientes das dietas neste estudo podem ter melhorado o sabor e incrementado o consumo, promovendo consequentemente o melhor desempenho dos peixes. Contrariamente aos resultados obtidos neste estudo, GAIOTTO (2005) e HISANO et al. (2007a) observaram menor consumo de ração dos tratamentos que continham parede celular na dieta em níveis de 2,5 e 5\% em pintados (Pseudoplatystoma corruscans), e em níveis de 0,1 a $0,3 \%$, para alevinos de tilápia do Nilo, respectivamente, em relação ao tratamento com

Tabela 2 - Valores de desempenho zootécnico e composição corporal de juvenis de tilápia do Nilo submetidos às dietas experimentais.

\begin{tabular}{|c|c|c|c|c|c|c|c|}
\hline & & \multicolumn{4}{|c|}{--------------------------------Tratamentos------------------------------- } & \multicolumn{2}{|c|}{---------Estatística---------. } \\
\hline & & $\mathrm{CO}$ & LI & LA & PC & Valor de F & $\mathrm{CV}(\%)$ \\
\hline & Peso inicial (g) & 52,40 & 51,60 & 52,20 & 52,30 & - & - \\
\hline & Peso final (g) & 153,17 & 160,47 & 166,90 & 183,33 & - & - \\
\hline \multirow{6}{*}{ 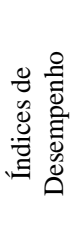 } & GP (g) & $100,77^{\mathrm{b}}$ & $108,87^{\mathrm{b}}$ & $114,70^{\mathrm{ab}}$ & $131,03^{\mathrm{a}}$ & $7,37 *$ & 7,18 \\
\hline & CMD (g) & $30,05^{b}$ & $33,32^{b}$ & $35,69^{\mathrm{ab}}$ & $40,83^{\mathrm{a}}$ & $10,62 * *$ & 6,9 \\
\hline & CAA & 1,34 & 1,41 & 1,44 & 1,41 & $0,42^{\text {ns }}$ & 7,93 \\
\hline & TEP & 2,56 & 2,35 & 2,36 & 2,30 & $1,12^{\mathrm{ns}}$ & 7,98 \\
\hline & TCE (\%dia) & $1,65^{\mathrm{b}}$ & $1,74^{\mathrm{b}}$ & $1,79^{\mathrm{ab}}$ & $1,93^{\mathrm{a}}$ & $8,32 * *$ & 3,98 \\
\hline & PBGP (\%) & $13,13^{b}$ & $13,82^{\mathrm{b}}$ & $14,45^{\mathrm{ab}}$ & $15,62^{\mathrm{a}}$ & $9,27^{* *}$ & 4,23 \\
\hline \multirow{4}{*}{ 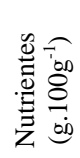 } & UM & 74,33 & 73,63 & 73,06 & 73,07 & $0,83^{\mathrm{ns}}$ & 4,33 \\
\hline & $\mathrm{EE}$ & 7,06 & 7,79 & 8,08 & 7,53 & $0,64^{\mathrm{ns}}$ & 12,42 \\
\hline & PB & $14,08^{\mathrm{b}}$ & $14,46^{\mathrm{b}}$ & $14,89^{\mathrm{ab}}$ & $15,67^{\mathrm{a}}$ & $7,75^{* *}$ & 2,88 \\
\hline & MM & 3,22 & 3,38 & 3,56 & 3,42 & $0,68^{\mathrm{ns}}$ & 8,66 \\
\hline
\end{tabular}

** significativo $\mathrm{P}<0,01$; * significativo $\mathrm{P}<0,05$; ns = não significativo.

Médias seguidas de letras distintas nas colunas diferem entre si pelo teste Tukey $(\mathrm{P}<0,05)$.

CO: controle; LI: levedura íntegra; LA: levedura autolisada; PC: parede celular.

UM: umidade; EE: extrato etéreo; PB: proteína bruta; MM: matéria mineral.

Composição centesimal corporal inicial (g 100g $\mathrm{g}^{-1}$ ): UM=75,68; EE=5,75; PB=15,80; MM=3,20.

Ciência Rural, v.40, n.5, mai, 2010. 
levedura íntegra e autolisada. Os autores relacionaram a menor ingestão do tratamento com parede celular em razão do elevado teor de ácidos nucleicos que podem diminuir a metabolização da proteína verdadeira.

Neste trabalho, o aumento no consumo de ração ocorreu concomitantemente com o maior ganho de peso, não alterando a conversão alimentar para todos os tratamentos $(\mathrm{P}>0,05)$, com valores médios entre 1,34 e 1,44, similares aos resultados apresentados por GAIOTTO (2005), que variaram entre 1,32 e 1,53. Entretanto, trabalhos de PEZZATO et al. (2006) e HISANO (2007a) demonstraram resultados melhores de conversão alimentar nos tratamentos com levedura autolisada e parede celular, quando comparados com a levedura íntegra.

Em estudo sobre a avaliação da composição nutricional e a digestibilidade aparente da levedura e seus derivados para a tilápia do Nilo, HISANO et al. (2008) verificaram que a levedura íntegra apresenta alto teor proteico $(49,17 \%)$ e boa digestibilidade proteica (69,64\%). Porém, a levedura autolisada contém menor teor de PB $(34,44 \%)$ e maior digestibilidade proteica (72,20\%), além de melhores valores de digestibilidade para matéria seca, energia e para grande parte dos aminoácidos essenciais e não essenciais, em razão da disposição de nutrientes resultante da lise da parede celular. A parede celular da levedura contém baixos valores proteicos $(34,82 \%)$ e apresentou menor digestibilidade (34,70\%), portanto os autores não recomendam sua utilização como fonte proteica para dietas de tilápias.

A parede celular contém alto teor de polissacarídeos não amiláceos, que podem prejudicar o aproveitamento de nutrientes, porém, observou-se no presente estudo, que o nível de inclusão desse ingrediente não prejudicou nenhum parâmetro de desempenho. Por outro lado, a presença de mananas e glucanas não digeríveis na parede celular da levedura pode beneficiar o animal (hospedeiro) por meio de uma seleção, estimulando o crescimento e/ou ativando o metabolismo ou ainda promovendo o desenvolvimento de um número limitado de bactérias do trato intestinal, melhorando o balanço intestinal do hospedeiro (LI \& GATLIN, 2003).

Os valores médios de ganho em peso apresentaram diferenças significativas quando submetidos à análise de variância $(\mathrm{P}<0,01)$. Os peixes alimentados com os tratamentos PC e LA ganharam mais peso (131,03 e 114,70g, respectivamente), porém peixes alimentados com LA não apresentaram diferenças significativas com os tratamentos LI e CO. Aplicando-se o índice relativo de comparação (IRC\%), atribuindo-se $100 \%$ à média do tratamento controle, observa-se que os tratamentos LI, LA e PC proporcionaram valores superiores de ganho de peso (8,04, 13,82 e 30,03\%, respectivamente) em comparação ao tratamento sem adição dos ingredientes teste.

A adição de $14 \%$ de levedura nas dietas de alevinos revertidos de tilápia do Nilo foi sugerida como o melhor nível de inclusão por FURUYA et al. (2000). A levedura possui elevado teor de ácidos nucleicos na parede celular e sua utilização na dieta de animais monogástricos deve ser feita com cautela, pois o excesso de ácido nucleico na dieta é tóxico (SCHULZ \& OSLAGE, 1976). No entanto, os efeitos tóxicos da levedura não foram relatados em peixes, provavelmente, em razão da alta atividade da uricase no fígado desses animais (RUMSEY etal., 1991; PERES \& OLIVA-TELES, 2003).

Neste estudo, não foi observada mortalidade de peixes em nenhum dos tratamentos, provavelmente em razão da permanência de condições laboratoriais adequadas ao desenvolvimento da tilápia do Nilo e dos componentes presentes na levedura e seus derivados (nucleotídeos, oligossacarídeos e complexos de proteínas com polissacarídeos), os quais estão relacionados a benefícios ao sistema imune, conferindo maior resistência frente a infecções bacterianas (SAKAI et al., 2001; ORTUÑO et al., 2002; LI \& GATLIN, 2004).

O maior ganho em peso dos peixes alimentados com dietas contendo parede celular e levedura autolisada também pode estar relacionado à maior ingestão de ração (Tabela 2) e consequentemente de proteína, o que se reflete nos maiores valores da taxa de crescimento específico (TCE) e proteína bruta no ganho de peso (PBGP), embora não tenha sido verificado efeito $(\mathrm{P}>0,05)$ dos ingredientes testados sobre a TEP. Os valores de TEP (2,30 a 2,56) obtidos no presente estudo, embora não diferentes entre os tratamentos, foram similares aos encontrados em pacu de 2,07 a 2,58 (PÁDUA, 1996) e de 2,15 a 2,55 (WATANABE, 2006), superiores aos observados por BACCARIN \& PEZZATO (2001), em tilápias do Nilo (1,00 a 1,71), e por GAIOTTO (2005), em juvenis de pintado (1,47 a 1,67).

Os valores de composição centesimal das tilápias antes e após a suplementação com levedura e derivados (Tabela 2) estão próximos aos citados por CONTRERAS-GUZMÁN (2002) para a tilápia do Nilo, ou seja: umidade entre 74 e $82 \mathrm{~g} 100 \mathrm{~g}^{-1}$, proteína bruta entre 14 e $19 \mathrm{~g} 100 \mathrm{~g}^{-1}$ e cinzas entre 0,7 e $3,1 \mathrm{~g} 100 \mathrm{~g}^{-1}$, com exceção dos lipídeos, que estão acima dos valores citados pelo autor (entre 0,3 e 5,5g $100 \mathrm{~g}^{-1}$ ), provavelmente pela inclusão de óleo de soja na dieta. Os peixes alimentados com a dieta contendo parede celular apresentaram maiores teores de proteína bruta 
no final do experimento $(\mathrm{P}>0,05)$ quando comparados com os tratamentos LI e CO e não diferiram estatisticamente $(\mathrm{P}<0,05)$ do tratamento LA. Contrariamente aos resultados obtidos, BACCARIN \& PEZZATO (2001) relataram menores conteúdos de proteína bruta e menores de lipídeos para tilápias do Nilo alimentadas com levedura desidratada de álcool, resultado que pode ser explicado pelo desbalanceamento de aminoácidos. LI \& GATLIN (2003), GAIOTTO (2005), PEZZATO (2006) e WATANABE (2006) não encontraram grandes diferenças na composição de filés de peixes alimentados com levedura, demonstrando que a levedura não afetou o metabolismo e consequentemente a deposição de nutrientes na carcaça.

\section{CONCLUSÃO}

A substituição de 25\% da proteína bruta na dieta pelos derivados da levedura de cana-de-açúcar, parede celular e levedura autolisada foi eficiente em promover melhor ganho de peso e maior deposição de proteína bruta no músculo de tilápias do Nilo.

A utilização de levedura íntegra e seus derivados não ocasionou prejuízo no desempenho zootécnico em comparação com a dieta controle. Dessa forma, esses resíduos do processamento da cana-deaçúcar podem ser utilizados na alimentação de juvenis de tilápia do Nilo sem prejuízo no desempenho e alterações na composição corporal.

\section{REFERÊNCIAS}

AOAC (Association of Official Agricultural Chemists). Official methods of analysis. Washington DC., 1990. 1298p.

ARANA, L.V. Princípios químicos de qualidade da água em aqüicultura. Florianópolis: UFSC, 2004. 231p.

BACCARIN, A.E.; PEZZATO, L.E. Efeito da levedura desidratada de álcool em dietas para tilápia do Nilo. Pesquisa Agropecuária Brasileira, v.36, p.549-556, 2001. Disponível em: <http://www.scielo.br/pdf/pab/v36n3/4800.pdf>. Acesso em: 15 jun. 2008. doi: 10.1590/S0100-204X2001000300021.

CONTRERAS-GUZMÁN, E.S. Bioquímica de pescados e invertebrados. Santiago: Universidad de Santiago de Chile, 2002. 309p.

FURUYA, W.M. et al. Níveis de levedura desidratada "spraydried” na dieta de alevinos revertidos de tilápia do Nilo (Oreochromis niloticus). Ciência Rural, v.30, n.4, p.699704, 2000. Disponível em: <http://www.scielo.br/pdf/cr/v30n4/ a24v30n4.pdf>. Acesso em: 20 mai. 2008. doi: 10.1590/ S0103-84782000000400024.

GATLIN III, D.G.; LI, P. Modulation of fish health and immune responses with non nutritive dietary supplements. In:
SIMPÓSIO DE NUTRIÇÃO E SAÚDE DE PEIXES, 2005, Botucatu, SP. Anais... Botucatu : Universidade Estadual Paulista, 2005. p.33-41.

GAIOTTO, J. R. Utilização de levedura de cana-de-açúcar (Saccharomyces cerevisiae) e seus subprodutos na alimentação de juvenis de pintado (Pseudoplatystoma corruscans). 2005. 87f. Dissertação (Mestrado em Zootecnia) - Universidade de São Paulo, SP.

HISANO, H. et al. Desempenho produtivo de alevinos de tilápiado-nilo alimentados com levedura e derivados. Pesquisa Agropecuária Brasileira, v.42, n.7, p.1035-1042, 2007a. Disponível em: <http://www.scielo.br/pdf/pab/v42n7/17.pdf>. Acesso em: 17 abr. 2008. doi: 10.1590/S0100204X2007000700017.

HISANO, H. et al. Levedura e zinco como pró-nutrientes em rações para tilápia-do-nilo (Oreochromis niloticus): aspectos hematológicos. Boletim do Instituto de Pesca, v.33, n.1, p.35-42, 2007b. Disponível em: <ftp://ftp.sp.gov.br/ftppesca/ 33_1_35-42.pdf>. Acesso em: 18 jun. 2008.

HISANO, H. et al. Composição nutricional e digestibilidade aparente da levedura íntegra, da levedura autolisada e da parede celular pela tilápia-do-nilo. Ciência Animal Brasileira, v.9, n.1, p.43-49, 2008. Disponível em: <http://www.revistas.ufg.br/ index.php/vet/article/view/3658/3424>. Acesso em: 20 jun. 2008.

LI, P.; GATLIN III, D.M. Evaluation of brewers yeast (Saccharomyces cerevisiae) as feed supplement for hybrid striped bass (Morone chrysops x M. saxatilis). Aquaculture, v.219, p.681-692, 2003. Disponível em: <http://www.sciencedirect.com/ science?_ob=MImg\&_imagekey=B6T4D-47VH5K8-13 \&_cdi $=4972$ \&_user $=8746464 \&$ \& pii $=$ S 00448486020065 $31 \&$ \& orig = search \&_cover Date $=04 \% 2$ F $02 \%$ 2 F2003\&_sk $=997809998 \&$ view $=c \& w c h p=d G L z V l z-$ zSkWb\&md5=bec08357bc7baf50bd9dccde9f8e2e55\&ie=/ sdarticle.pdf $>$. Acesso em: 15 jun. 2008. doi: 10.1016/S00448486(02)00653-1.

LI, P.; GATLIN III, D.M. Dietary brewers yeast and the prebiotic Grobiotic ${ }^{\mathrm{TM}} \mathrm{AE}$ influence growth performance, immune responses and resistance of hybrid striped bass (Morone chrysops x M. saxatilis) to Streptococcus iniae infection. Aquaculture, v.231, p.445456, 2004. Disponível em: <http://www.sciencedirect.com/ science?_ob=MImg\&_imagekey=B6T4D-49TRNB9-B3 \&_cdi $=4972$ \&_user $=8746464 \&$ \& pii $=$ S00448486030056 $84 \&$ \& orig = s e a r ch \&_cover Date $=03 \% 2$ F $05 \% 2$ F 2004\&_sk $=997689998 \&$ view $=c \& w c h p=d G L b V z b-$ zSkWz\&md5=e53a8705330dbfe71106de108cee881e\&ie=/ sdarticle.pdf $>$. Acesso em: 8 mai. 2008. doi: 10.1016/ j.aquaculture.2003.08.021.

MEDRI, V. et al. Growth of tilapia (Oreochromis niloticus) fed with different levels of alcohol yeast. Revista Brasileira de Biologia, v.60, n.1, p.113-121, 2000. Disponível em: <http:/ /www.scielo.br/pdf/rbbio/v60n1/a13v60n1.pdf>. Acesso em: 15 jul. 2008. doi: 10.1590/S0034-71082000000100014.

MEURER, F. et al. Utilização de levedura spray dried na alimentação de alevinos de tilápia do Nilo (Oreochromis niloticus L.). Acta Scientiarum, v.22, n.2, p.479-484, 2000. Disponível em: <http://periodicos.uem.br/ojs/index.php/ ActaSciBiolSci/article/viewFile/2995/2117>. Acesso em: 10 jun. 2008. 
NATIONAL RESEARCH COUNCIL. Committee on Animal Nutrition. Nutrient requirements of fish. Washington, DC: National Academic, 1993. 115p.

OLIVA-TELES, A.; GONÇALVES, P. Partial replacement of fishmeal by brewers yeast (Saccharomices cerevisae) in diets for sea bass (Dicentrarchus labrax) juveniles. Aquaculture, v.202, n.3-4, p.269-278, 2001. Disponível em: <http:// w w w. s c i e n c e d i r e c t c c o m/ science?_ob=MImg\&_imagekey=B6T4D-44CMFSF-8$3 \&$ cdi $=4972 \&$ \&user $=8746464 \&$ \&pii $=$ S 004484860100 $7773 \&$ _ orig = b r ow se $\&_{-}$c o ver D a te $=11$ \%2F01\%2F2001\&_sk=997979996\&view=c\&wchp=dGLbVlbzSkWb\&md5=6b8e386ae8077e482ed3dfad77e08cc3\&ie =/ sdarticle.pdf>. Acesso em: 15 jun. 2008.

ORTUÑO, J. et al. Oral administration of yeast, Saccharomyces cerevisiae, enhances the cellular inate immune response of gilthead seabream (Spaurus auratus L.). Veterinary Immunology and Immunopathology, v.85, p.41-50, 2002. Disponível em: <http:// www.sciencedirect.com/science?_ob=MImg\&_imagekey=B6TD544GF16F-1-M\&_cdi=5189\&_user $=8746464 \&$ \&ii $=$ S01652427010 $04068 \&$ \& orig=search \&_cover Date $=02 \% 2$ F $28 \%$ 2 F $2002 \&$ sk $=999149998 \& v i e w=c \& w c h p=d G L b V z b-$ zSkWA\&md5=533b31d3e7a1d43f7d92897f5ece5e26\&ie $=/$ sdarticle.pdf $>$. Acesso em: 01 jun. 2008.

OZÓRIO, R.O.A. et al. Efeito de diferentes níveis de levedura desidratada (Saccharomyces cerevisae) sobre o desempenho e composição corporal da Tilápia-do-Nilo (Oreochromis niloticus) revertida sexualmente. In: CONGRESSO IBERO-AMERICANO VIRTUAL DE AQÜICULTURA, 2., 2003, Zaragoza, España. Anais... Zaragoza : Universidad de Zaragoza, 2003. p.89-98.

PÁDUA, D.M.C. Utilização de levedura alcoólica (Saccharomy cerevisae) como fonte protéica na alimentação de juvenis de pacu (Piaractus mesopotamicus, Pisces, Teleostei): Aspéctos metabólicos e desempenho produtivo. 1996. 120f. Dissertação (Mestrado em Aquicultura) Centro de Aquicultura da Universidade Estadual Paulista, SP.

PEREIRA-DA-SILVA, E.M.; PEZZATO, L.E. Respostas da tilápia do Nilo (Oreochromis niloticus) à atratividade e palatabilidade de ingredientes utilizados na alimentação de peixes. Revista Brasileira de Zootecnia, v.29, p.1273-1280, 2000 Disponível em: <http://www.scielo.br/pdf/rbz/v29n5/5646.pdf>. Acesso em: 15 jun. 2008. doi: 10.1590/S151635982000000500003 .
PERES, H.; OLIVA-TELES, A. The effect of dietary ribonucleic acid incorporation in performance of European sea bass (Dicentrarchus labrax) juveniles. Aquaculture, v.215, n.1-4, p.245-253, 2003. Disponível em: <http://www.sciencedirect.com/ science?_ob=MImg\&_imagekey=B6T4D-45PTT5D-1$1 \&$ \&_di $=4972 \&$ \&user $=8746464 \&$ \&_pii=S 00448486 $02001308 \&$ orig=search \&_coverDate $=01 \% 2$ F10\%2F2003\&_sk $=997849998 \& v i e w=c \& w c h p=d G L b V l W-$ zSkWb\&md5=4dd7e0888bd12a54ce9a70ad4cf9f260\&ie $=/$ sdarticle.pdf $>$. Acesso em: 15 jun. 2008. doi: S00448486(02)00130-8.

PEZZATO, L.E. et al. Levedura em dietas para alevinos de tilápia do Nilo. Veterinária e Zootecnia, v.13, n.1, p.84-94, 2006. Disponível em: <http://www.fmvz.unesp.br/revista/ volumes/vol13/VZ13\%282006\%29_84-94.pdf>. Acesso em 25 mai. 2008

RUMSEY, G.L. et al. Effect of high dietary concentration of brewers dried yeast on growth performance and liver uricase in rainbow trout (Oncorhynchus mykiss). Animal Feed Science and Technology, v.33, p.177-183, 1991.

SAKAI, M. et al. Immunoestimulant effects of nucleotide isolated from yeast RNA on carp, Cyprinus carpio L. Journal of Fish Disease, v.24, p.433-438, 2001. Disponível em <http: /www3.interscience.wiley.com/cgi-bin/fulltext/120704508/ PDFSTART>. Acesso em: 29 abr. 2008.

SAS. STATISTICAL ANALYSIS SYSTEM. User's guide 6. 12.ed. Cary, North Carolina, 2006. V.2.

SCHULZ, E.; OSLAGE, H.J. Composition and nutritive value of single-cell protein (SCP). Animal Feed Science and Technology, v.1, n.1, p.9-24, 1976.

WATANABE, A.L. Suplementação de levedura desidratada (Saccharomyces cerevisiae) e derivados na alimentação de juvenis de pacu (Piaractus mesopotamicus). 2006. 82f. Dissertação (Mestrado em Zootecnia) - Universidade de São Paulo, SP.

YAMADA, E.A. et al. Composição centesimal e valor protéico de levedura residual da fermentação etanólica e de seus derivados. Revista de Nutrição, Campinas, v.16, n. 4, p.423-432, 2003. Disponível em: <http://www.scielo.br/pdf/rn/v16n4/ a06v16n4.pdf>. Acesso em: 15 jun. 2008. doi: 10.1590/S141552732003000400006. 